\title{
Financial Exclusion Analysis Based on Urban and Rural Differences and Influencing Factors
}

\author{
Lili Jiang \\ Management College, China West Normal University, Nanchong, 637009, China
}

Keywords: Urban, Rural, Difference, Financial exclusion, Influencing factors

\begin{abstract}
With the development of reform and opening up, China's financial system continues to improve, urban and rural finance enjoy certain development. But because of various factors, urban and rural financial development also experienced some problems, especially in the more backward rural areas, promotion of financial products and services is more difficult, which increased the seriousness of the disparity between urban and rural financial exclusion. In this regard, the paper analyze financial exclusion caused by unbalanced development between urban and rural development from the perspective of urban and rural differences, find specific factors contributing to financial exclusion, and explore effective strategies to tackle financial exclusion.
\end{abstract}

\section{Introduction}

Financial exclusion generally refers to situations where the subject cannot have financial products and financial services from mainstream financial institutions because they don't have suitable access. Based on this view, we can see that financial exclusion includes geographic exclusion, evaluation exclusion, price exclusion, conditions exclusions, marketing exclusion and self- exclusion. From urban and rural development, we can see that there are great differences in geographic environment, conditions, pricing, marketing and evaluation resulting urban and rural financial exclusion.in-depth study and resolve of China's urban and rural financial exclusion, and actively improve the urban and rural financial system is necessary to promote stable and rapid development of China's economic and financial health, to achieve early socialism in our country.

\section{An overview of financial exclusion}

Financial exclusion refers to the inability of certain groups in society into the financial system, inability to obtain the necessary financial services in proper form. It appeared in the 1990 of the 20th century. Leyshon and Thrift from United Kingdom pointed out in the course of financial geography research and define the phenomena as vulnerable or disadvantaged groups in society, restricted by geographic accessibility, were excluded from the mainstream financial services institutions. After that, many academics involved in the study of financial exclusion, defined the dimensions evaluation criterion on the basis of geographic accessibility of financial exclusion, namely geography exclusion, condition exclusion, evaluating exclusion, marketing, prices exclusive, self- exclusion [1].

\section{Measurement and analysis of financial exclusion on differences between urban and rural China}

In order to crack financial exclusion on differences between urban and rural scientifically, analyze their impact factor, explore effective measures to solve the problem, we need to calculate the financial exclusion in urban and rural differences.

\section{Construction of evaluation index system of financial exclusion on urban and rural difference}

Academic community presented its dimensions evaluation criterion of financial exclusion on the basis of geographical accessibility as geographic exclusion, evaluation exclusion, conditions exclusion, marketing evaluation and self- exclusion. But from the reality in China's urban and rural 
development, construction of evaluation index system of financial exclusion on differences between urban and rural should be geographical exclusion, evaluation and condition exclusion, marketing exclusion, self - exclusion.

Geographic exclusion. Base on per-capita savings in China's provinces, autonomous regions and municipalities, geographical differences are presented as lack of nearby access to financial services or smaller local financial institutions, which resulted in geographical exclusion.

Assessment and condition exclusion. In simple terms, risk assessment would exclude financial subject with some financial demands; condition assessment is some economic subjects are excluded from financial services under conditions of financial products. Judging from per-capita loan situation in Chinese provinces, autonomous regions, municipalities, evaluation and conditional exclusion do exist.

Marketing exclusion. Judging from the number of service personnel in city and rural of China's provinces, autonomous regions and municipalities, some financial subject for personal reasons is excluded from product, which constitutes marketing and market exclusion.

Self - exclusion. Judging from urban and rural per-capita education spending in China's provinces, autonomous regions and municipalities, we can learn that some economic subject give up financial products and services, which is the self - exclusion.

\section{Calculation and analysis of financial exclusion on China urban and rural differences}

Calculation index for financial exclusion of Chinese urban and rural differences

In view of the above four micro-evaluation indicators in financial exclusion evaluation indicators system, measuring index for financial exclusion: Suppose our urban and rural differences in evaluation of financial exclusion degree is $\mathrm{n}$, the n-th measurement value is $D_{n}$; suppose w represents the weight, the weights of the n-th dimension is $W_{n}$, index formula would be obtained, namely:

$$
\sum D_{n}=W_{n} \frac{X_{n}-m_{n}}{M_{n}-m_{n}}
$$

Note: $M_{n}$ is maximum value of $n$-th dimension evaluation; $m_{n}$ is minimum value of n-th dimension evaluation; $X_{n}$ is the real value of n-th dimension evaluation index; ${ }^{W_{n}}$ should meet the conditions: $0<W_{n} \leq 1$.

In order to accurately measure urban and rural differences of financial exclusion, we also need a clear weight of each dimension.

First is data standardization. Suppose we have $\mathrm{P}$ of urban and rural financial exclusion differential dimension, then $\mathrm{p}$-dimensional random vector is composed of: $X=\left(X_{1} X_{2}, \ldots, X_{P}\right)^{T}$; assumes estimated sample number is $\mathrm{n}$, vectors of $\mathrm{n}$ is: $X_{i}=\left(X_{1 P} X_{2 P}, \ldots, X_{i P}\right)^{T}$, which can estimate the sample matrix, namely:

$$
\mathrm{Z}_{i j}=\frac{x_{i j}-\overline{x_{j}}}{s_{j}}, i=1,2, \ldots, n ; j=1,2, \ldots, P
$$

Next, find the correlation coefficient matrix. Use standard data matrix to calculate related matrix $(\mathrm{R})$, which is expressed as:

$$
R=\left[r_{i j}\right]_{P} x P=\frac{Z^{T} Z}{n-1}, r_{i j}=\frac{\sum Z_{k j} \bullet Z_{k j}}{n-1} ; i, j=1,2, \ldots, P
$$

Finally, calculate dimensions weight. Change previously mentioned standardized index variables to conversion component, the conversion formula is:

$$
U=Z_{i}^{T} b_{j}^{0},=1,2, \ldots, m
$$


According to the above formula, calculate the weight sum of main components of the $\mathrm{m}$, to get dimensions weight, that is, for variance contribution ratio of each principal component [3].

Estimation and analysis of financial exclusion of the provincial urban and rural differences

City and country are different in the 4 aspects: education level, per capita savings, per capita loan and service personnel number; so this paper selected related statistics data for 29 provinces and cities between 2000-2014 years, using STATA to calculate urban and rural feature value of education level, per capita savings, per capita loan, and service personnel number in 29 Chinese provinces and cities, we calculated features value for education level $\left(X_{1}\right)$ of $50.51 \%$, per capita savings $\left(X_{2}\right)$ features value for $35.12 \%$, both ratios include all information in all indexes. Thus, we can be sure, 2 main components are as follows:

First main component: $F_{1}=0.5046 X_{1}+0.3227 X_{2}-0.7914 X_{3}+0.0891 X_{4}$

Second main component: $F_{2}=0.4113 X_{1}+0.7548 X_{2}+0.5416 X_{3}-0.0057 X_{4}$

Test with KMO and SMC, and analyze test results, we can find China's serious financial exclusion in urban and rural differences, also we can see that financial exclusion has much to do with provincial and municipal economic development level [2]. Specifically, existence of financial exclusion of differences between urban and rural development is affected by education level, personal savings, economic entities, financial products and services, national policies and other aspects, these aspects accelerate financial exclusion. In the process of sustainable development of China's economy, geography, economy, financial services in urban area are better than that in rural area, resulting in urban and rural differences, which greatly increased the severity of financial exclusion of urban and rural differences.

\section{Factors related to financial exclusion from Chinese urban and rural differences}

Based on the above analysis of financial exclusion from differences between urban and rural China, we can learn that main influence factors causing serious financial exclusion are:

\section{External environmental factors}

Financial exclusion caused by external environment is primarily due to economic developments and Government fiscal policy. Finance is born in the process of economic development, and economic development also determines the financial development. In complicated market economy in China, the financial development is deeply affected, both promotes the generation of financial exclusion. For Macro-regulate and control the economy, execution of Government's fiscal policy is in accordance with market conditions, such as economy trend, manpower cost, geographical location, technical developments, and implementation of the policy will have a greater impact which makes it easier to the generation of financial exclusion [5].

\section{Individual capability}

Factors of individual capability is the difference of personal competence, which includes income, employment, education, age and gender that are likely to have impact on financial exclusion. In terms of personal income, personal income can reflect State or regional economic development level to a certain extent. Individuals with higher income are likely to have diversified financial needs. Financial institutions will includes these individuals in the financial services. On the contrary, individuals with lower income are less likely to have those financial needs, they would be most likely excluded from those service. These differences will inevitably cause financial exclusion. Such as the employment situation, in countries with good employment, their residents are likely getting good jobs, and getting huge incomes, they will inevitably be regard as financial institution clients, otherwise they will be excluded from the financial institutions and financial services. Employment situation is grim in China now, which makes it difficult for many citizens to get good jobs, so they are likely to be excluded from financial services, which induce the generation of financial exclusion. Therefore, personal competence has a great impact on financial exclusion [3]. 


\section{Effective countermeasures to address financial exclusion of Chinese urban and rural differences}

Facing differences between urban and rural economic development that leads to financial exclusion, effective measures should be taken to resolve the situation, so that a sound financial system can be established, promoting healthy, stable and rapid economic development in China.

\section{Increase availability of financial products and services}

At present, China is in the middle of urban and rural structural transformation and urbanization, rapid economic growth in provinces and municipalities are pushing forward the development in financial sector. But for effective solution to the problem of financial exclusion, we still need to coordinate development in urban and rural area, increase feasibility of financial products and services, and reduce differences in urban and rural economic development. Specifically, in consideration of urban economic development and financial products in cities, vigorously support the development of potential rural financial institutions or encouraging State-owned financial institution at relatively slow rural areas, launch financial products and services applicable to the area and similar to products and service in cities to promote rural economic development. In addition, promote people-centred new urbanization, strengthen rural financial development in the town, which is also an integrated and effective measure for urban and rural development, to address financial exclusion resulting from differences between urban and rural development [4].

\section{Create new financial products and services}

The financial exclusion resulting from differences between urban and rural development have great relations with different financial products and services provided by urban and rural financial institutions. Urban dwellers have fixed assets as financing security; financial institutions can introduce a variety of financial products and services to meet their needs without worrying about the impact of financial risk. But it's different in rural areas, rural residents depend on agriculture only, which is a weak industry as the financial security with a lot of uncertainty and unable to meet complicated risk assessment procedures in financial institutions, so that financial products and services provided by financial institutions is limited to loans, insurance, future goods.

So, financial exclusion is inevitable. To change the situation of single financial products and service by rural financial institutions, we should actively innovate rural mortgage guarantees system and strengthening education of financial knowledge in rural area, change financial concept of rural area residents, so that they can accept new way of mortgage guarantees, then actively innovate financial products and financial service, diversify financial products and financial service, stimulate rural economic development, gradually resolve financial exclusion resulting from city and rural differences.

\section{Strengthen the financial system}

Implementation of urban development, new rural construction in China, policy to benefit farmer and strengthen agriculture can relieve financial exclusion resulting from urban and rural differences to a certain extent. Based on this situation, we should emphases the role of government, urge Chinese government to vigorously support rural economic development, and make rural finance a priority, implement appropriate farmer-benefiting policy to promote and stimulate rural financial development, these measures can strengthen building of rural financial service supporting facilities and financial system, promote fast, health and stable development of rural finance, shorten distance of urban and rural economy, this is also conducive to resolve financial exclusion resulting from city and rural differences [5].

\section{Concluding remarks}

Continuous development of reform and opening up produces more differences between urban and rural economic development in China, resulting in serious financial exclusion, which is very 
detrimental to healthy, stable, sustained and rapid development of our country's economy. In this regard, we should gradually eliminate urban and rural differences by ensuring availability of rural financial products and services, creating new financial products and services, strengthening the financial system and other measures and gradually solve the problem of financial exclusion to create the conditions for China's economic development. In short, we should actively address financial exclusion resulting from the differences between urban and rural development.

\section{Acknowledgments}

Foundation project: This paper is one of the progressive achievements of financial exclusion and farmer-benefiting financial system research financed by China West Normal University scientific projects (NO.:13D025).

\section{References}

[1] Li Xiaohong. Socio-Demographic Characteristics and Environmental Concerns: Based on the Data in Rural Areas. Population • Resources and Environment in China, 2011,21 (12): 121-128.

[2] Jiang Mei, Min Zhu, Quan Hong. Comparative Study of English Learning Strategies of College Students from Rural and Urban Sources --Empirical Analysis Based on Yunnan University. Agricultural Education, 2011 (6): 75-78.

[3] Liang Haiyan, Li Cansong. Why Floating Population Wondering Among Rural and Urban Areas?--Analysis Based on Data from Six Provinces in Central and Western China. Population and Development, 2015, 21 (1): 32-40,11.

[4] Li Ying, Li Qiang. Rural and Urban Teachers Professional Development Based on Cultural Change. Journal of Liaoning Institute of technology (Social Science Edition), 2012,14 (6): 135-137.

[5] Wang Shuchun, Wang Jun. Pursuit of Welfare and Sustainable Development of Urbanization in China-- Analysis from the Perspective of Sustainable Development. Journal of Xuzhou Normal University (philosophy and Social Science Edition), 2011,37 (4): 136-142. 